\title{
[SHORT COMMUNICATION]
}

\section{Body Muscle-Cell Differentiation from Coelomic Stem Cells in Colonial Tunicates}

\author{
Yasuo M. Sugino, Miyako Matsumura and Kazuo Kawamura* \\ Laboratory of Cellular and Molecular Biotechnology, Faculty of Science, \\ Kochi University, Kochi 780-8520, Japan
}

\begin{abstract}
Body muscle-cell differentiation was ultrastructurally examined in palleal buds of the colonial tunicate Symplegma reptans. Undifferentiated coelomic cells accumulate near the primordial oral siphon and associate with the basal lamina beneath the epidermis. They initially display the characteristics of hemoblast cells that have a large nucleus with a prominent nucleolus and narrow cytoplasm filled with polysomes. However, they soon become unique due to the development of an indented contour of the nucleus. When the basal lamina of the epidermis develops into the fibrous extracellular matrix (ECM), the muscle precursor cell has the deeply-notched nucleus, and thick and thin filaments in the cytoplasm facing the ECM. Collagen fibril-like structures appear in the ECM. Myofilaments are arranged with the ratio of thick to thin filaments being 1:2.5. Dense bodies and plaques become evident before the oral siphon is perforated. These results show that in S. reptans, the sphincter muscle cells arise from undifferentiated hemoblasts, and that their differentiation begins with a morphological change in their nuclei. Epidermal cells and/or the ECM may have an inductive effect on muscle cell differentiation.
\end{abstract}

Key words: body muscle, colonial tunicate, ECM, hemoblast, nuclear indentation, myofilament

\section{INTRODUCTION}

Asexual reproduction involves the propagation of clonal individuals from somatic cells instead of germ cells (Berrill, 1950). It utilizes the regenerative potential of somatic cells to reconstruct tissues and organs (Morgan, 1901; Kawamura and Fujiwara, 1995). In colonial tunicates, several kinds of multipotent cells and tissues are capable of renewing and remodeling the body architecture (Nakauchi, 1982; Kawamura and Nakauchi, 1991; Kawamura and Fujiwara, 1994). Multipotent epithelial cells constitute the epicardium in Polyclinidae and Polycitoridae (Brien, 1968), the atrial epithelium in Botryllidae (Berrill, 1941; Izzard, 1973; Casagrande et al., 1993; Burighel et al., 1998) and Styelidae (Sugimoto and Nakauchi, 1974; Kawamura and Fujiwara, 1994), and the septum in Perophoridae and Clavelinidae (Lefevre, 1898; Koguchi et al., 1993).

Another type of multipotent cell is present in the coelomic body cavity in both colonial and solitary tunicates. It is referred to as a hemoblast and is characterized by the presence of a large nucleus with a prominent nucleolus and narrow cytoplasm filled with polysomes (Wright, 1981). A variety of tissues and organs such as the gonad (Mukai and Watanabe, 1976; Sunanaga et al., 2006, 2007), the pericardium (Nunzi et al., 1979), the pyloric gland (Kawamura and

\footnotetext{
* Corresponding author. Phone: +81-88-844-8696; Fax : +81-88-844-8696; E-mail: kazuk@cc.kochi-u.ac.jp
}

Nakauchi, 1986), and bud vesicle (Oka and Watanabe, 1957; Freeman, 1964; Sabbadin et al., 1975) differentiate from undifferentiated coelomic cells.

Symplegma reptans is a transparent colonial tunicate (Sugimoto and Nakauchi, 1974). Buds arise from the right ventral body wall of the parent organism. Their organogenesis has been described by light-microscopic observation (Kawamura and Nakauchi, 1986). For example, the body musculature is recruited from mesenchymal cells at every budding cycle. Precursor cells of the oral sphincter (e.g., Fig. 1E) appear at the stage when a siphon anlage is established, but it is uncertain whether these mesenchymal cells are undifferentiated cells or muscle-lineage cells conveyed from the parental zooid. Colonial tunicates may be useful to study the manner in which body muscle cells originate and develop.

In the present study, we ultrastructurally examined the appearance and differentiation of body muscle precursor cells during blastogenesis in S. reptans. The results provide evidence of a new repertoire of hemoblasts in colonial tunicates.

\section{MATERIALS AND METHODS}

Colonies of Symplegma resptans were attached to glass plates and cultured in Uranouchi Inlet near the Usa Marine Biological Institute of Kochi University.

The animals were prefixed in $2.5 \%$ glutaraldehyde in $0.1 \mathrm{M}$ phosphate buffer ( $\mathrm{pH} 7.4$ ) containing $2 \% \mathrm{NaCl}$ for $10 \mathrm{~min}$ at room temperature and on ice for approximately $1 \mathrm{~h}$. At the end of prefixation, the specimens were cut into small pieces, detached from the glass plates, and rinsed for approximately $30 \mathrm{~min}$ with cold, buffered 


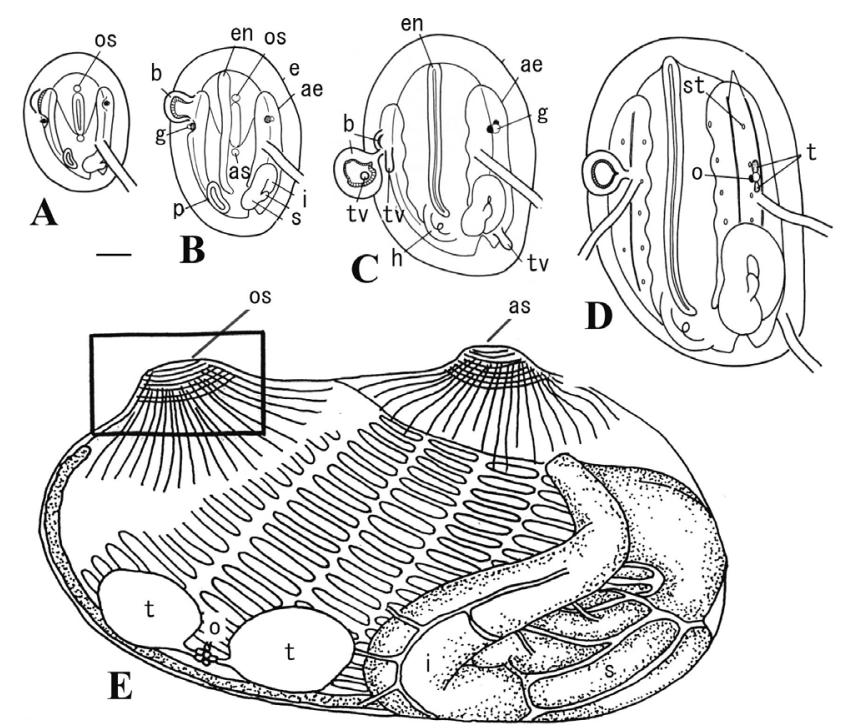

Fig. 1. Schematic presentation of developing buds and a zooid in S. reptans. (A)-(D) Ventral view, redrawn from Kawamura and Nakauchi (1986). Bar, $0.2 \mathrm{~mm}$. (E) Lateral view, redrawn from Tokioka (1953). (A) Stage 9. Siphon anlagen and bud primordium appear. (B) Stage 10. The endostyle appears. (C) Stage 11. The heart begins to beat. (D) Stage 12. Stigmata anlagen (gill slits) appear. (E) Stage 13, an adult zooid. Muscle fibers develop especially around both siphons. This study involved sphincter muscle cells of the oral siphon (boxed). ae, atrial epithelium, as, atrial siphon; b, bud; e, epidermis; en, endostyle; g, gonad; h, heart; i, intestine; o, ovary; os, oral siphon; $p$, pericardium; s, stomach; st, stigmata; t, testis; tv, test vessel.

salt solution. They were postfixed in $1 \%$ osmium tetroxide in $0.1 \mathrm{M}$ phosphate buffer ( $\mathrm{pH} 7.4)$ on ice for $2 \mathrm{~h}$, dehydrated in a graded series of cold ethanol, cleared in propylene oxide, and embedded in modified Spurr's resin (Kushida, 1980). Some of the specimens were stained en bloc with uranyl acetate prior to dehydration. Thin sections were stained with both uranyl acetate and lead citrate and examined under a JEOL JEM-100U electron microscope.

\section{RESULTS AND DISCUSSION}

The lifespan of blastozooids of S. reptans comprises 15 developmental stages (Kawamura and Nakauchi, 1986); here, we deal with stages $9-13$. Stage 9 is characterized by the appearance of oral and atrial siphon anlagen and by the evagination of the first bud (Fig. 1A). The endostyle appears at stage 10 (Fig. 1B), and the heart begins to beat at stage 11 (Fig. 1C). Stigmata anlagen (gill slits) appear at stage 12 (Fig. 1D). At stage 13, the stigmata are perforated, ciliary movement begins, and the siphons open; thus the animal attains functional maturity.

\section{Hemoblast aggregation}

The primordial oral siphon appears as a small epidermal disc that adheres to the prebranchial epithelium, and then both epithelia become continuous (Fig. 2A). Coelomic cells accumulate around the disc (Fig. 2B, C). They are approximately $6 \mu \mathrm{m}$ in diameter and have a large nucleus with a prominent nucleolus (Fig. 2B, C). The cytoplasm is filled with free polysomes (Fig. 2B, D). The mitochondria and endoplasmic reticulum are both poorly developed. These cytolog- ical features are identical to those of hemoblasts, which are referred to as coelomic undifferentiated cells in tunicates (Wright, 1981). However, when the cells associate with the basal lamina of the epidermis, they become unique because the nucleus develops a slightly uneven contour, with the notched portion of the nucleus often facing the epidermis (Fig. 2D, E arrows). This is the first unique cytological feature of muscle precursor cells.

Previously, light-microscopic studies have indicated that in colonial tunicates, the body wall muscle of adult animals arises from free coelomic cells (Pizon, 1893; Berrill, 1941; Kawamura and Nakauchi, 1986). However, the cytological features of these cells have remained unclear. In the present study, ultrastructural examination revealed that in $S$. reptans, the sphincter muscle cells are derived from undifferentiated hemoblasts.

In the solitary tunicate Halocynthia roretzi, body muscle cells originate from two distinct larval cell types, the trunk lateral cells and the trunk ventral cells, of which the trunk lateral cells give rise to the oral sphincter cells (Hirano and Nishida, 1997). The trunk lateral cells also differentiate into coelomic cells. It is interesting that in both postembryonic development and blastogenesis of tunicates, body muscle cells share a common cell lineage with coelomic cells.

\section{Nuclear indentation}

At stage 10, the nucleus of muscle precursor cells becomes deeply notched (Fig. 2F, G). This nuclear indentation is observed only in cells surrounding the rudimentary oral and atrial siphons, which indicates that in S. reptans, the notched nuclear morphology was specific to body muscle-cell differentiation. In S. reptans, muscle fibers other than those associated with the oral and atrial siphons run along the dorsal body wall. As they are few in number and poorly organized, we could not follow accurately the origin and differentiation of these muscle cells. In Botryllus schlosseri, the cardiac muscle cells and pericardium arise from aggregated hemoblasts (Nunzi et al., 1979). Nuclear indentation is absent in these hemoblasts. In mammals, the nucleus of blood neutrophils undergoes morphological changes during differentiation. Nuclear indentation is influenced by cytoskeletal structures such as microtubules (Olins and Olins, 2004) and by lamin, a component of the nuclear envelope that renders the envelope rigid (Yabuki et al., 1999). In the present study, there was no evidence of cytoskeletal involvement in the nuclear concavity of muscle precursor cells.

\section{Appearance of myofilaments}

Myofilaments are another feature of muscle precursor cells at stage 10. The thick, homogeneous basal lamina (0.1-0.2 $\mu \mathrm{m}$ in thickness) lies beneath the epidermal cells of the disc-like siphon anlage (Fig. 2F, arrowheads). In muscle precursor cells, thin and thick myofilaments appear in the cytoplasm adjacent to the basal lamina (Fig. 2G arrows). The thin and thick filaments are approximately $6-7$ and 20 $\mathrm{nm}$ in diameter, respectively (Fig. $2 \mathrm{H}$ ). Both these filaments appear to have a relatively ordered arrangement. This mode of development is a contrast to that of the larval tail and zooidal heart muscles, in which myofilaments appear randomly in the cytoplasm (Terakado, 1972; Cavey and Cloney, 1974; Nunzi et al., 1979). 

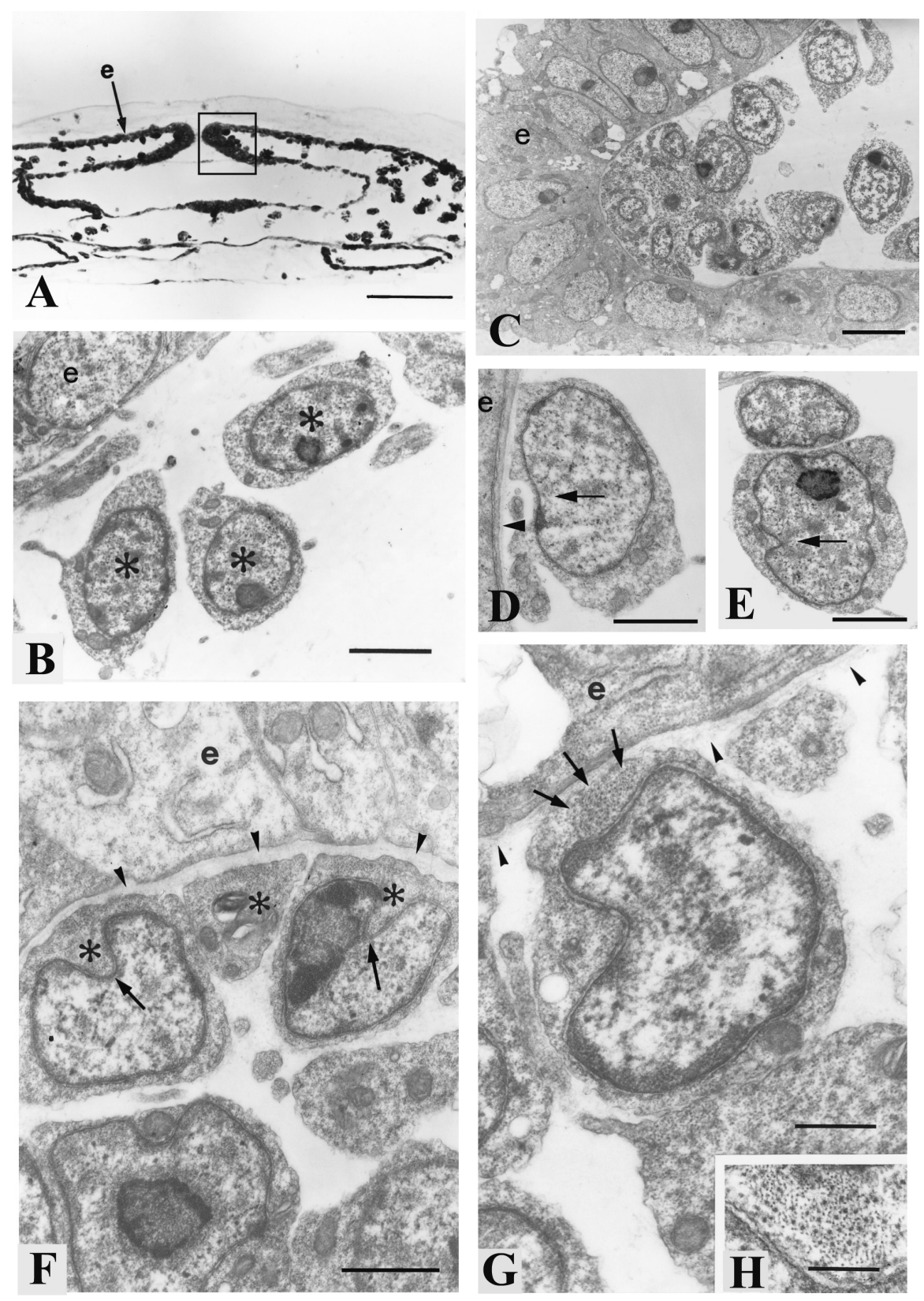

Fig. 2. Fine structure of muscle precursor cells in the oral siphon anlage. (A) Semi-thin section of an oral siphon anlage (boxed) at stage 10. e, epidermis. Bar, $50 \mu \mathrm{m}$. (B) Hemoblasts (asterisks) located near the epidermis (e) at stage 9. They possess oval nuclei with a prominent nucleolus. Organelles are few in the cytoplasm. Bar, $2 \mu \mathrm{m}$. (C) Hemoblasts aggregating in the epidermal pocket (e) of a siphon anlage at stage 10. Bar, $5 \mu \mathrm{m}$. (D) A hemoblast with the nucleus deformed to some extent (arrow) at stage 10. It is associated with the epidermis (e) via the thin basal lamina (arrowhead). Bar, $2 \mu \mathrm{m}$. (E) A hemoblast with the nucleus indented (arrow) at stage 10. Bar, $2 \mu \mathrm{m}$. (F) Hemoblasts (asterisks) associated with the thick basal lamina (arrowheads) of epidermal cells (e) at late stage 10. Their nuclei facing the basal lamina are deeply indented. Bar, $1 \mu \mathrm{m}$. (G) A muscle precursor cell with myofilaments (arrows) in the cytoplasm adjacent to the epidermis (e) at late stage 10. Bar, $0.5 \mu \mathrm{m}$. (H) Myofilaments as observed under higher magnification. Thin and thick filaments appear simultaneously and have an ordered arrangement. Bar, $0.2 \mu \mathrm{m}$.

\section{Myocyte differentiation}

At stage 11, the number of myofilaments conspicuously increases in differentiating myocytes (Fig. 3A, asterisks). They appear consistently in the restricted area of the cytoplasm, facing the basal lamina of the epidermis. The thick basal lamina contains granular bodies (Fig. 3A, arrowheads), and develops into the extracellular matrix (ECM) by stage 12 (Fig. 3B). Epidermal cells extend minute projections into the ECM (Fig. 3B, arrowheads). The ECM contains collagen fibril-like structures that run parallel to the surface of the myocytes (Figs. 3C, arrowheads; 3D).

At stages 12-13, several dense bodies (Fig. 3C, circles) and dense plaques (Fig. 3C, arrows) are observed in single sections in S. reptans. According to Terakado (1987), dense bodies in $\mathrm{H}$. roretzi are structures that are anchored by thin filaments, similar to the Z-bands of striated muscles in vertebrates, whereas dense plaques are the dense surface bodies to which thin and intermediate filaments are 

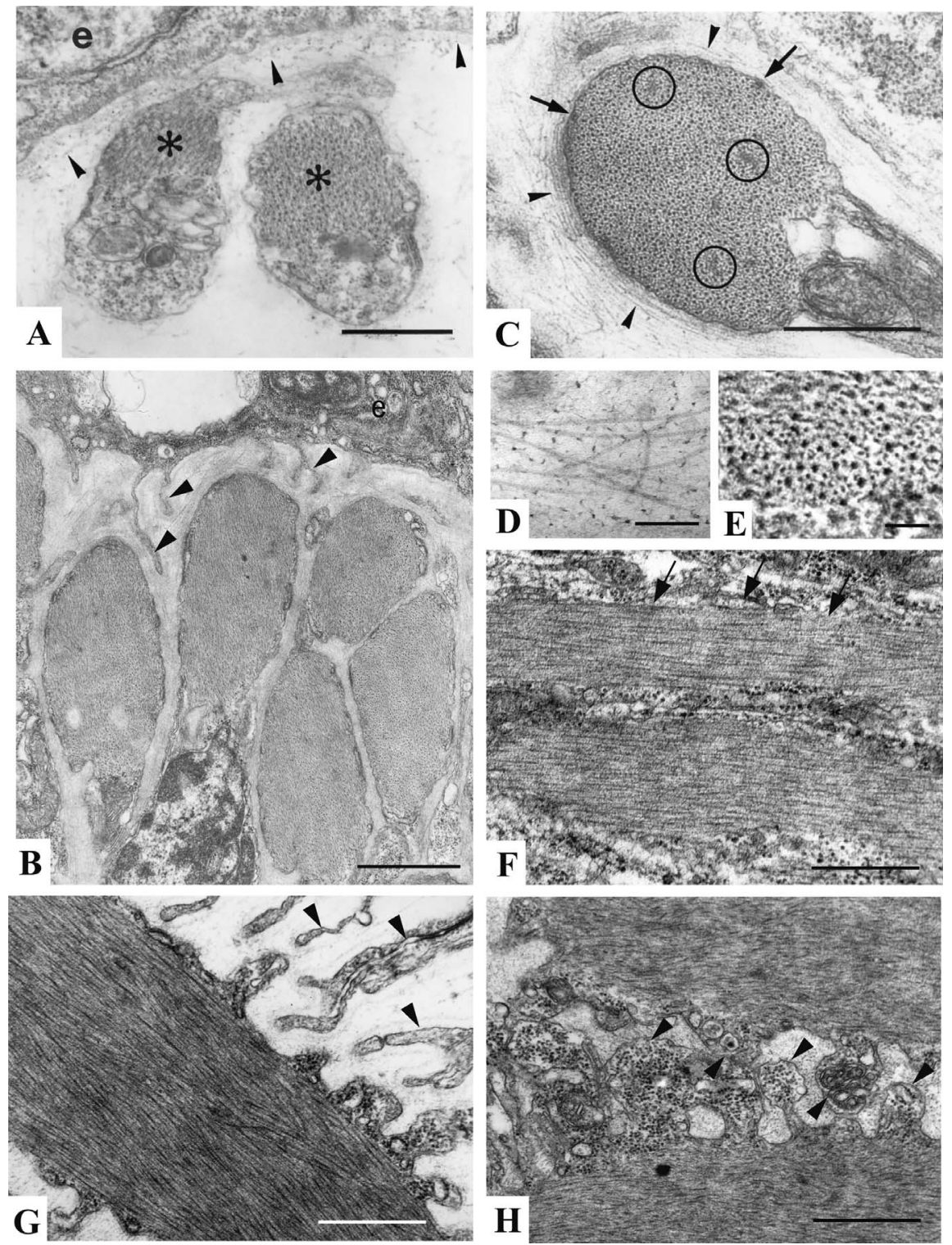

Fig. 3. Differentiation of sphincter muscle cells in the oral siphon anlage. (A) Myocytes with an increasing number of myofilaments (asterisks) at stage 11. They are associated with the basal lamina (arrowheads) that becomes thick and possesses granular bodies beneath the epidermis (e). Bar, $0.5 \mu \mathrm{m}$. (B) Myocytes in which myofilaments occupy most of the cytoplasm at stage 12. Epidermal cells (e) extend thin projections into the ECM (arrowheads). Bar, $1 \mu \mathrm{m}$. (C) Cross section of a muscle cell at late stage 12. Dense bodies (circle) and plaques (arrows) are visible. Collagen fibril-like structures (arrowheads) run parallel to the cell surface. Bar, $0.5 \mu \mathrm{m}$. (D) Higher magnification of collagen fibril-like structures in the ECM at late stage 12. Bar, $0.2 \mu \mathrm{m}$. (E) Higher magnification of cross section of thick and thin filaments at late stage 12. Bar, $0.1 \mu \mathrm{m}$. (F) Longitudinal section of muscle fibers at late stage 12. They have periodic dark bands that run obliquely (arrows). Bar, $0.4 \mu \mathrm{m}$. (G) Longitudinal section of a muscle cell. It receives many projections from epidermal cells (arrowheads) at stage 13. Bar, $0.5 \mu \mathrm{m}$. (H) Boundary of neighboring muscle cells at stage 13. Cells have bleb-like protrusions (arrowheads) in which free ribosomes are observed. Bar, $0.5 \mu \mathrm{m}$.

attached. In $H$. roretzi, the ratio of thick to thin filaments in myocytes is approximately $1: 6$, and these filaments have a rosette-like appearance (Terakado and Obinata, 1987). In contrast, in S. reptans, the ratio is $1: 2.5$ at most (Fig. 3E), a value resembling that of striated muscles in vertebrates (Terakado, 1987). In $H$. roretzi, intermediate $(10 \mathrm{~nm})$ filaments are located in the relatively wide interspaces between bundles of thin and thick filaments (myofibrils) (Terakado and Obinata, 1987). In S. reptans, myocytes do not have such interspaces, and the thin and thick filaments are densely distributed in the cytoplasm (Fig. 3C, E).
In longitudinal sections of muscle cells of $S$. reptans, muscle fibers have periodic dark bands that run obliquely (Fig. 3F, arrows). Epidermal cells extend fine projections to muscle cells (Fig. 3G, arrowheads). Ribosome-containing bleb-like protrusions are observed between neighboring muscle cells (Fig. $3 \mathrm{H}$, arrowheads). Unfortunately, we could not detect the multinucleated sphincter muscle cells in $S$. reptans. However, multinucleation is common in the bodywall smooth muscle in $H$. roretzi (Shinohara and Konishi, 1982). This may occur due to cell fusion, as observed in skeletal muscle cells (Terakado and Obinata, 1987). 


\section{Conclusion}

Thus far, body muscle cells in tunicates have been of particular interest primarily for two reasons. (1) They are multinucleated, although they are smooth muscle cells (Shinohara and Konishi, 1982). (2) They contain the actinlinked regulatory system (troponin complex) required for contraction (Toyota et al., 1979; Endo and Obinata, 1981), although the myosin light-chain phosphorylation system generally regulates myosin ATPase in smooth muscle cells.

The present study using the colonial tunicate S. reptans adds several novel findings. First, the body muscle is reconstructed at every budding cycle by coelomic undifferentiated cells-hemoblasts. Previously, light-microscopic studies did not reveal the nature of muscle precursor cells in the hemocoel (Pizon, 1893; Berrill, 1941; Kawamura and Nakauchi, 1986). Second, it is at stage 9 that hemoblasts gather around the oral siphon anlage, although they were observed at stage 11 by light microscopy. Third, muscle precursor cells are unique due to the presence of a notched nucleus. Fourth, myofilaments appear at stage 10, when the nucleus of the muscle precursor cell is deeply indented. Finally, circumstantial evidence suggests that epidermal cells and/or the basal lamina may have an inductive effect on the differentiation of body muscle cells.

\section{ACKNOWLEDGMENTS}

We would like to express special thanks to Professor Emeritus Dr. M. Nakauchi for introducing us to colonial tunicates. YMS also thanks Dr. T. Fujiwara of Ehime University for helpful discussions. We are grateful to the staff of Usa Marine Research Center for providing us with many conveniences.

\section{REFERENCES}

Berrill NJ (1941) The development of the bud in Botryllus. Biol Bull 80: $169-184$

Berrill NJ (1950) The Tunicata, With an Account of the British species. Ray Society, London

Brien P (1968) Blastogenesis and morphogenesis. In "Advances in Morphogenesis Vol 7" Ed by M Abercrombie, J Brachet, TJ King, Academic Press, New York, pp 151-203

Burighel P, Lane NJ, Zaniolo G, Manni L (1998) Neurogenic role of the neural gland in the development of the ascidian, Botryllus schlosseri (Tunicata, Urochordata). J Comp Neurol 394: 230-241

Casagrande L, Martinucci GB, Burighel P (1993) Origin and differentiation of branchial stigmata in the compound ascidian Botryllus schlosseri. Anim Biol 2: 111-121

Cavey MJ, Clony RA (1974) Fine structure and differentiation of ascidian muscle. II Morphometrics and differentiation of the caudal muscle cells of Distaplia occidentalis tadpoles. J Morphol 144: 23-70

Endo T, Obinata T (1981) Troponin and its components from ascidian smooth muscle. J Biochem 89: 1599-1608

Freeman $\mathrm{G}$ (1964) The role of blood cells in the process of asexual reproduction in the tunicate Perophora viridis. J Exp Zool 156:157-184

Hirano T, Nishida H (1997) Developmental fates of larval tissues after metamorphosis in ascidian Halocynthia roretzi. I. Origin of mesodermal tissues of the juvenile. Develop Biol 192:199-210

Izzard CS (1973) Development of polarity and bilateral asymmetry in the palleal bud of Botryllus schlosseri (Pallas). J Morphol 139: $1-26$

Kawamura K, Fujiwara S (1994) Transdifferentiation of pigmented multipotent epithelium during morphallactic development of budding tunicates. Int J Dev Biol 38: 369-377
Kawamura K, Fujiwara S (1995) Cellular and molecular characterization of transdifferentiation in the process of morphallaxis of budding tunicates. Semin Cell Biol 6: 117-126

Kawamura K, Nakauchi M (1986) Development of spatial organization in palleal buds of the compound ascidian Symplegma reptans. Biol Bull 171: 520-537

Kawamura K, Nakauchi M (1991) Homeostatic integration of stem cell dynamics during palleal budding of ascidians. Zool Sci 8: 11-22

Koguchi S, Sugino YM, Kawamura K (1993) Dynamics of epithelial stem cell in the process of stolonial budding of the colonial ascidian, Perophora japonica. Mem Fac Sci Kochi Univ Ser D 14: 7-14

Kushida $\mathrm{H}$ (1980) An improved embedding method using ERL 4206 and Quetol 653. J Electron Microsc 29: 193-194

Lefevre G (1898) Budding in Perophora. J Morphol 14: 367-424

Morgan TH (1901) Regeneration. The MacMillan Company, New York, pp 316

Mukai $\mathrm{H}$, Watanabe $\mathrm{H}$ (1976) Studies on the formation of germ cells in a compound ascidian, Botryllus primigenus Oka. J Morphol 148: $337-362$

Nakauchi M (1982) Asexual reproduction of ascidians: its biological significance, diversity, and morphogenesis. Amer Zool 22: 753-763

Nunzi MG, Burighel P, Schiaffino S (1979) Muscle cell differentiation in the ascidian heart. Develop Biol 68: 371-380

Olins AL, Olins DE (2004) Cytoskeletal influences on nuclear shape in granulocytic $\mathrm{HL}-60$ cells. BMC Cell Biol 5: 30

Pizon A (1893) Histoire de la blastogenese chez les Botrylloides. Ann Sci Nat 14:1-386

Przybylski RJ, Blumberg JM (1966) Ultrastructural aspects of myogenesis in the chick. Lab Invest 15: 836-863

Sabbadin A, Zaniolo G, Majone F (1975) Determination of polarity and bilateral asymmetry in palleal and vascular buds of the ascidian Botryllus schlosseri. Develop Biol 46: 79-87

Shimada $Y$ (1971) Electron microscope observation on the fusion of chick myoblasts in vitro. J Cell Biol 48: 128-142

Shinohara Y, Konishi K (1982) Ultrastructure of the body-wall muscle of the ascidian Halocynthia roretzi: smooth muscle cell with multiple nuclei. J Exp Zool 221: 137-142

Sugimoto K, Nakauchi M (1974) Budding, sexual reproduction, and degeneration in the colonial ascidian, Symplegma reptans. Biol Bull 147: 213-226

Sunanaga T, Saito Y, Kawamura K (2006) Postembryonic epigenesis of Vasa-positive germ cells from aggregated hemoblasts in the colonial ascidian, Botryllus primigenus. Dev Growth Differ 48: 87-99

Sunanaga T, Watanabe A, Kawamura K (2007) Involvement of vasa homologue in germline recruitment from coelomic stem cells in budding tunicates. Dev Genes Evol 217: 1-11

Terakado K (1972) Cytological and ultrastructural studies on muscle differentiation in the ascidian, Perophora orientalis. Dev Growth Differ 14: 1-23

Terakado K (1987) Fine structure of ascidian smooth muscle. Zool Sci 4: 751-761

Terakado K, Obinata T (1987) Structure of multinucleated smooth muscle cells of the ascidian Halocynthia roretzi. Cell Tissue Res 247: 85-94

Tokioka T (1953) Ascidians of Sagami Bay. Iwanami Shoten, Tokyo

Toyota N, Obinata T, Terakado K (1979) Isolation of troponin-tropomyosin-containing thin filaments from ascidian smooth muscle. Comp Biochem Physiol 62B: 433-441

Wright RK (1981) Urochordates. In "Invertebrate Blood Cells Vol 2" Ed by NA Ratcliffe, AF Rowley, Academic Press, London, pp 565-626

Yabuki M, Miyake T, Doi Y, Fujiwara T, Hamazaki K, Yoshioka T, Horton AA, Utsumi K (1999) Role of nuclear lamins in nuclear segmentation of human neutrophils. Physiol Chem Phys Med NMR 31: 77-84

(Received November 15, 2006 / Accepted January 15, 2007) 